\title{
Developing a GIS-integrated Tool to Obtain Citizens' Input in On-site Participation-Learnings from Participatory Urban Planning of a Large City
}

\author{
Gerrit C. Küstermann \\ Universität Hamburg \\ kuestermann@,informatik.uni-hamburg.de
}

\author{
Eva A. C. Bittner \\ Universität Hamburg \\ bittner@,informatik.uni-hamburg.de
}

\begin{abstract}
Informal participation procedures are used by authorities to obtain citizen input and to ease formal plan approval procedures and decision-making at an early stage of urban planning projects. Participation in spatial planning is no longer conceivable without geo-referenced contributions. Hence, digital tools such as geographic information systems (GIS) and multi-touch tables (MTT) are increasingly being used to complement traditional tools. These technologies offer advantages such as visual presentations based on spatial and planning data that can help to simplify and illustrate complex issues. However, the integration of GIS and MTT in onsite participation is challenging, since media disruptions and missing tool capabilities impede the collection of citizens' input and subsequent processing. We address these challenges by eliciting requirements and prototypically developing a GIS-integrated tool that enables citizens to comment via GIS and MTT in a context-related and intuitive way using mobile devices at participatory planning events.
\end{abstract}

\section{Introduction}

In Germany, a planning permit procedure is legally obligatory for large development projects, in that public consultation must be carried out for affected citizens [8]. In this process, those entitled to object are only informed after the planning has been completed and are not involved during the planning process. Citizens then have the right to have their objections dealt with. This approach, commonly known as "Decide, Announce, Defend", is still used today in the planning of large-scale projects, but it is facing increasing democratic resistance and impedes optimal planning results [32, 42]. Communication, information and participation are attributed central importance, especially in large-scale projects, since the sole legitimation of such projects by procedures is no longer sufficient. This leads to the need for informal participation processes in decision- and policy-making that complement formal procedures [7, 32]. Although this imperative, known in urban planning theory as communicative or collaborative turn, has been discussed since the 1990 s at the latest $[16,33]$, it was only the new construction of Stuttgart's main railway station (Stuttgart 21) and the conciliation procedure in 2011 that triggered a broad discussion in politics and administration on how to improve participation processes in early planning stages in Germany $[4,6]$. A major driver of this paradigmatic shift is the use of digital technologies [1] to support civic participation processes (e-participation) both on-site (i.e. during local events and workshops) and off-site (i.e. online citizen participation, before and after on-site events) [2].

Especially when the question "Where?" is at the center of the participatory process, e.g. in spatial planning and urban development, traffic planning and environmental protection, the visualization and communication of spatial contexts and site-related planning scenarios form the focal points of the discourse. At on-site events, such as participatory planning workshops, on which this research focuses, public officials and planners often use traditional tools such as large-format city and plan maps on paper and haptic models made of wood and cardboard to provide location-based information. However, digital geographic information systems (GIS) and large multitouch tables (MTT) are increasingly being used to complement traditional tools in informal participation formats $[15,22]$. These technologies support flexible, processoriented planning and offer permanent access to an upto-date database. Further advantages, such as the extensive analysis and presentation options of various planning scenarios and alternatives as well as the subsequent easy and cost-effective online publication, make GIS so attractive for citizen participation. In the future, it is conceivable that they could entirely replace traditional tools. However, the demands on digital GIS are as manifold as the potential benefits. Especially, if digital elements are integrated into a participatory overall strategy, it is necessary that online and offline elements are logically intertwined so that the respective advantages of both elements can be 
exploited and citizens and authorities can effectively collaborate [11, 40]. Against this background, however, it became evident to the authors of this paper that the potentials of GIS and MTT in the interaction among and between citizens and authorities during on-site planning workshops could only be partially exploited though (see section 4. Requirements and concept). The elementary interlocking of digital tools and personal interactions has not yet been adequately realized, due to limited tool capabilities and problems caused by media disruptions.

In order to address these identified problems, we follow a Design Science Research (DSR) approach to design a GIS-integrated software tool that allows users (participating citizens) to comment plans, drafts and models on GIS and MTT in a context-related (e.g. geo-referenced) and intuitive way using mobile devices. In the following, the fundamentals of informal citizen participation and GIS within the scope of e-participation are discussed first and the methodology is presented afterwards. Subsequently, the requirements and an initial concept for a GIS-integrated tool in the context of on-site participatory planning and their implementation are described. The paper ends with a conclusion, limitations and outlook.

\section{Study background}

\subsection{Integrated informal citizen participation}

"Treating public participation as a desirable but neglected step in the planning process has the effect of entrenching the dominance of professionals and of formal planning processes, suggesting a level of agency that is at odds with the way in which cities actually develop" [36, p. 566]. Particularly, established formal participation procedures do not meet the needs of modern societies characterized by direct and immediate communication and interaction. Moreover, they leave a number of promising technological opportunities unused [19]. Informal processes, by contrast, usually offer more freedom and the necessary flexibility to take advantage of these opportunities. Figure 1 illustrates a good practice for integrated multi-phase participation processes that combine online and offline elements. Despite this, there is no blueprint for informal citizen participation processes. Prior to each participation process, public project managers and officials consult each other in an internal process across the respective authorities and departments and outline a scheme based on key questions such as, what is the main objective, how much and at what point in the process can citizens participate and what measures and steps are necessary to achieve this. That is, the level of participation (e.g. informative, consultative, collaborative [34]), the number and nature of events and meetings and the use of online participation always depends on the stakeholders involved, (potential) conflicts and the complexity of the planning project. However, there is always at least one informative opening event and a program focused on communication and outreach to citizens, e.g. activating interviews to increase awareness of a proposal [34].

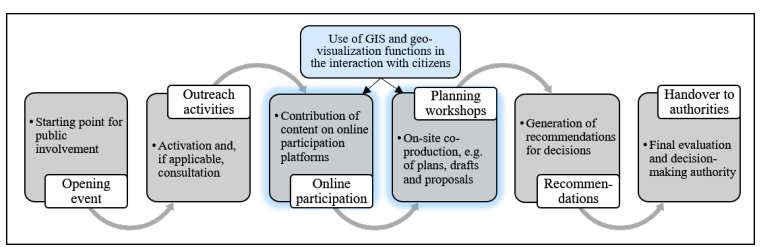

Figure 1. Good practice for informal participation processes. Own illustration based on [2].

Interactive public events on planning related issues, e.g. planning workshops, and often one or more online participation phases follow. Citizens must be involved as early as possible [4], ideally when there exists only a "blank page". However, if the process is complex, it is necessary to offer templates and proposals to citizens to support the understanding and facilitate engagement. As part of a large city's district restructuring process, for example, the adjacent local traffic junction was to be optimized in terms of traffic flow. For this reason, various feasible alternatives for road planning were shown online to enable citizens to express concrete criticism and contribute ideas and suggestions for improvement on these alternatives based on their local knowledge and experiences. In this case more than 1,100 comments were received, which were consolidated and analyzed. From these, revised variants, which comply with the legal and financial requirements, were developed in cooperation with an engineering office, which in turn formed the basis for a following co-creative/co-productive planning workshop [38]. The processing of data and information, i.e. the analysis and transfer of comments on planning alternatives and variants between the participation phases and the extrapolation of plans, is consequently a major task. At the end of the informal participation process, the developed recommendations are submitted to the responsible authorities, e.g. district committee, for formal plan approval procedures and final decision-making.

\subsection{E-participation \& GIS in urban planning}

Advances in information and communication technologies (ICT) have created a call for planning processes to improve participatory methods. The use of technologysupported methods in participatory urban planning is often referred to as e-planning or e-participation. The influence of web-technologies on urban planning is so great that scholars describe it as a paradigm shift $[1,27]$. In this sense, new ICT have brought new types of data to local 
and urban administration $[21,28]$, new means of obtaining data or facilitating participation [3, 30], and new views on the relationship between the virtual and the real in planning and urban design $[28,41]$, which help to cope more reasonably with the complexities of planning. In this light, it is generally recognized that new digital technologies, with their diversity of tools (GIS, mobile applications, crowdsourcing, collaboration platforms, etc.) [5, $11,19,25]$, have the potential to facilitate public engagement in participatory planning [28].

The means by which participation is implemented are changing substantially. Against this change, e-participation concentrates on new tools, structures and the timing of participation in urban development processes [27, 39]. Often GIS-based tools are implemented at the beginning of the process to foster collaborative decision-making, but do not work in a dialogue-oriented manner, and the interaction between citizens and planners tends to be onedirectional $[27,35]$. Nonetheless, participation in spatial planning is simply no longer conceivable without georeferenced contributions, since modern geospatial applications have changed the way citizens can actively participate in urban planning. Particularly the utilization of virtual environments and geo-visualization in the processes of citizen participation is a key development in participatory planning, as it allows the investigation and visualization of urban complexities and can help to simplify and illustrate complex issues [23, 28]. Web-based digital systems integrate technologies and tools for data acquisition, storage and handling, and e-participation procedures. The complementary character of most of these tools recommends their integration into platforms based on GIS [20]. However, the implementation of digital tools raises a number of challenges that planners and public authorities should consider [12, 28].

In the field of e-participation, there is a complex interaction between information technology, services, stakeholders, public officials and citizens. In the case of personal interactions, such as during public events and workshops, various factors can impede a comprehensive exchange of ideas and thus the development of effective decisions and plans [29]. Hence, the design of digital elements has a major influence on the success of a participation process. Barriers to participation can only be overcome, if the respective elements are designed in such a way that they are geared to the user's digital life and experience, e.g. no special articulation nor professional competence should be a condition for participation [23].

\section{Methodology}

We follow the information systems (IS) DSR paradigm to build a useful and novel IT artifact in the field of e-participation $[17,31]$. In DSR, IT artifacts can be or contribute to foundational theories, frameworks, instruments, constructs, models, methods, and instantiations $[18,31]$. In our iterative research approach, we take the DSR three-cycle view, which comprises the relevance cycle, design cycle, and rigor cycle [17].

In the relevance cycle, we identified a set of unsolved problems regarding the purposeful utilization of GIS applications for MTT with respect to challenges that emerge in on-site citizen participation in spatial planning processes. This problem identification is grounded on observations and interviews. Specifically, we observed three different citizen participation workshops in urban planning projects (see table 2). Further, to elicit insights about the meaning of the observed behaviors, interactions, and processes during these workshops, we conducted informal, conversational interviews with on-site experts, officials and citizens [10].

In the design cycle, the real world problems drive the development of our artifact. Our artifact is the concept and a prototypical instantiation of a GIS-integrated tool for facilitating interaction among participants, supporting capturing citizens' feedback and further processing in the course of citizen participation and planning. For the construction of the artifact, we first derive explicit prescriptions (e.g. principles of form and function) in the mode of design requirements (Rs), which can further be regarded as a process step in extending the applicable knowledge base $[9,13]$. These Rs are elaborated based on semistructured interviews and group discussions with domain experts (see table 1).

\section{Table 1. Experts and their competencies.}

\begin{tabular}{|l|l|}
\hline No. & \multicolumn{1}{|c|}{ Field of expertise } \\
\hline E1 & $\begin{array}{l}\text { Employee of a public agency that provides the geospatial data and } \\
\text { geodata applications for city agencies. In the department, she/he is } \\
\text { product owner for the central geodata portal of the city and GIS- } \\
\text { based systems and applications for civic participation. That is, } \\
\text { she/he is responsible for technical development and setup of tools. } \\
\text { The work also includes data standardization and various digitiza- } \\
\text { tion processes in the authority. }\end{array}$ \\
\hline E2 & $\begin{array}{l}\text { Employee who consults and supports municipal bodies (e.g. dis- } \\
\text { trict authorities, state enterprises) in citizen participation processes } \\
\text { to enhance the effectiveness and appeal of participation. She/he } \\
\text { supports citizen participation events and workshops by the author- } \\
\text { ity for which she/he works. }\end{array}$ \\
\hline E3 & $\begin{array}{l}\text { Manager in the authority responsible for the realization of projects } \\
\text { to improve and maintain the built environment and technical infra- } \\
\text { structure in accordance with legal requirements. She/he leads a } \\
\text { team of } 12 \text { people and is responsible for the planning and outcome } \\
\text { of citizen participation in the associated projects. }\end{array}$ \\
\hline E4 & $\begin{array}{l}\text { Project staff in the same authority like E3. She/he (engineer) is } \\
\text { concerned with the communication with engineering and planning } \\
\text { offices. She/he serves as an expert at citizen participation events to } \\
\text { e.g. explain technical plans to citizens. }\end{array}$ \\
\hline E5 & $\begin{array}{l}\text { Software developer with many years of experience in the develop- } \\
\text { ment and design of GIS also in the realm of construction planning } \\
\text { and large touch screens. She/he has realized several projects in col- } \\
\text { laboration with public authorities. }\end{array}$ \\
\hline
\end{tabular}


During the interviews and discussions, the core statements were noted down directly and verbatim statements were also transmitted, but to a minor extent (simultaneous protocol). A team of three researchers who complemented and corrected each other prepared the reports (team protocol) [37]. Following established principles of qualitative content analysis [24], the subsequent analysis of the protocols was completed when no additional new Rs could be identified and categorized inductively. During the following artifact conceptualization phase, the Rs were discussed and prioritized together with the expert group. In addition, the Rs implemented in the prototypical instantiation were iteratively evaluated with the experts throughout the design process to improve the artifact.

Ensuing the design activities, the comprehensive knowledge base is expanded via the rigor cycle by adding prescriptive knowledge to literature [14]. Furthermore, the developed artifact contributes utility for the class of identified problems in the practical environment via the relevance cycle.

\section{Requirements and concept}

By means of the interviews conducted and the qualitative analysis, the observations of the events (see table 2) could be further enhanced and synthesized into initial requirements. Each R shown in table 3 is exemplified by at least one expert statement. It should be noted that statements can naturally correspond to several categories, as they are either multifaceted in content or constitute interrelated Rs [24]. In the further part of this section we outline the main findings of the analysis and present the initial tool concept based on the Rs.

Requirements analysis. The main objectives of participatory planning processes are to obtain meaningful input, e.g. comments with suggestions for improvements and concrete ideas from citizens to ease formal approval procedures and legitimize decision-making. It is important to create an awareness of the feasibility of ideas. This prevents unrealistic requests and disappointment of citizens. Therefore, different methods and tools are utilized online and on-site. In this context, all interviewed domain experts agreed that the use of digital spatial data is very important to support the discussion with citizens and that better tools lead to more effective participation processes. GIS-based applications for MTT, which display planning-relevant information, are a way to transport information and explain specific decisions while sitting together with citizens - better than saying, "that's just not possible". It was found, however, that particularly in the phase of elaboration and discussion of planning alternatives there is a lack of options for digitally capturing com- ments and visualizing them for participants. Even if digital GIS and MTT are used, comments have to be written with a pen on posters or note cards and posted to movable bulletin boards. Based on their practical workshop experience, the experts reported that information and, in some cases, complete comments got lost in the course of the discourse before they were documented. Against this background, it is also problematic that the handwritten notes are neither plan-integrated, i.e. linked to specific planning alternatives and variants, nor contextualized with topic-specific (e.g. categories) and exact geospatial information. Thus, discussions on planning alternatives based on the comments provided are not possible or only to a limited extent. Moreover, it is difficult for newly arriving citizens to understand the current state of discussion and participate. The unstructured, unspecific and not contextualized comments also impede the ad hoc analysis within workshops, e.g. to identify relationships and key issues, and complicate the presentation of the summarized results in plenary sessions. In addition, the subsequent processing, i.e., the digital extrapolation of plans for the next phase of the process, depends on time-consuming post-digitization of comments, usually by commissioned agencies, and data integration. Further, the experts were in consensus that tools for capturing comments digitally must be designed in such a way that everyone can use them easily. Thus, the usability for citizens as well as officials, planners etc., is an important factor. On the one hand, citizens who only come in touch with the tool once or a few times must be able to use it intuitively without a learning effort. On the other hand, officials who are not technology-savvy must be able to administer the settings and offer tool support to citizens. In summary, it is desirable that the advantages of face-toface interaction between citizens and public authorities are sustained and improved by digital tools and geo- and planning-data. To this end, media disruptions within the working processes need to be reduced or, at best, eliminated to allow efficient integration into the participation process.

Initial conceptualization. Our approach is to base the generation of annotations during online participation and workshops on an identical database, so that media disruptions can be prevented and both data sets can be displayed simultaneously. For this purpose, we rely on a purely digital, GIS-integrated tool to input and display comments via MTT. We differentiate between citizens on the one hand and organizers or moderators of workshops as users of the tool on the other hand. Since it would be very difficult to realize that several citizens type in their comments on a MTT at the same time, due to the limited space and the active interaction with the GIS, the input of comments directly at the MTT-interface appears to make little sense. The challenge of simultaneous input of comments by different citizens is solved via the use of 
Table 2. Comparison of the urban planning projects and observed workshops.

\begin{tabular}{|c|c|c|c|c|}
\hline No. & Planning objective and type of workshop & Process and methods of the workshop & Tools used in the workshop & Excerpt of the main observations \\
\hline 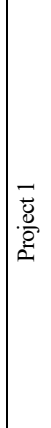 & $\begin{array}{l}\text { - Redesign of an important traffic junction and } \\
\text { central location in a district with the focus on } \\
\text { optimizing bus and bicycle traffic. } \\
\text { - Planning workshop, as part of the overall pro- } \\
\text { cess after an opening event and a first work- } \\
\text { shop, with the objective of discussing an earlier } \\
\text { planning alternative, evaluating a new alterna- } \\
\text { tive and elaborating new approaches. } \\
\text { - Determination of recommendations for the sub- } \\
\text { sequent formal planning process. }\end{array}$ & $\begin{array}{l}\text { - Officials and experts from an engineering office presented the re- } \\
\text { view results of a planning alternative that was the favorite from the } \\
\text { previous workshop but proved to be unfeasible after the subse- } \\
\text { quent review. Three variants of a new planning alternative were } \\
\text { presented and the citizens were handed a flyer with the relevant in- } \\
\text { formation. Plenary discussions after each presentation followed. } \\
\text { - Based on the three variants of the new alternative, moderated dis- } \\
\text { cussions were held in small groups (citizens, experts, officials) to } \\
\text { reach a mutual understanding and to elaborate suggestions for im- } \\
\text { provement. Each workstation had tables with large printouts of the } \\
\text { variants, with a moderator from an agency and professional sup- } \\
\text { port from officials of the authority. } \\
\text { - Following the group work, the experts presented the main results } \\
\text { in a plenary session. Participants from the respective groups sup- } \\
\text { plemented the presentations as required. }\end{array}$ & $\begin{array}{l}\text { - Digital projector } \\
\text { - Poster, large format plans } \\
\text { and paper maps on tabletops } \\
\text { (i.e. road cross sections, site } \\
\text { plans and maps of traffic } \\
\text { flow) } \\
\text { - Printed material, paper note } \\
\text { cards, pens, pins, movable } \\
\text { stands with bulletin boards }\end{array}$ & $\begin{array}{l}\text { - The participating citizens had a high degree of local knowledge. } \\
\text { - It was noticeable that there were often questions about the changes in the } \\
\text { planning alternatives, which were not presented clearly enough on the pro- } \\
\text { vided handouts. } \\
\text { - Many critical queries and comments on the review results from citizens dur- } \\
\text { ing the first plenary discussion. } \\
\text { - By means of traffic flow maps and road cross sections, officials attempted to } \\
\text { present the variants as intelligibly as possible and highlight the differences } \\
\text { both to the status quo and to the other variants. It was noticeable, however, } \\
\text { that the experts still found it somewhat difficult to explain the plans to the citi- } \\
\text { zens. There were many interposed questions and the presentation of the indi- } \\
\text { vidual variants took a lot of time. In addition, the participants found it difficult } \\
\text { to remember and distinguish the many details of the three variants. Therefore, } \\
\text { it seemed hardly possible to judge how the variants differed and which one } \\
\text { could be most suitable. }\end{array}$ \\
\hline & $\begin{array}{l}\text { - Reconstruction of one of the main traffic arter- } \\
\text { ies of the city. The aim of the planning and par- } \\
\text { ticipation was to keep the burden on residents, } \\
\text { commuters and other road users as low as possi- } \\
\text { ble and to obtain ideas for the redesign of the } \\
\text { streetscape. } \\
\text { - The participation process comprised two online } \\
\text { participation phases. The first phase was fol- } \\
\text { lowed by local activities to inform citizens and } \\
\text { obtain input. In the second phase, the alterna- } \\
\text { tives developed by the planners could be com- } \\
\text { mented and evaluated by the citizens. A first } \\
\text { public meeting and workshop followed this. } \\
\text { - The ensuing planning workshop (observed) in- } \\
\text { corporated the previous results with the aim of } \\
\text { discussing the planning alternatives, identifying } \\
\text { advantages and disadvantages and further po- } \\
\text { tential for improvement. }\end{array}$ & $\begin{array}{l}\text { - After the opening by the officials in the plenum, citizens could in- } \\
\text { form themselves about the current planning status. For the visuali- } \\
\text { zation of the main road, a large printed plan map was used. The } \\
\text { comments from the online participation phase were manually } \\
\text { pasted into this map. Citizens could add further comments by an- } \\
\text { notating on the map and note cards. } \\
\text { - For the following workshop, separate stations were set up where } \\
\text { citizens could work together and with officials on planning alterna- } \\
\text { tives and improvements: in three rooms, individual sections of the } \\
\text { planning and the respective alternatives were presented on posters } \\
\text { and smaller plan maps on tabletops. On the posters, pro and contra } \\
\text { columns were placed in which citizens could write their argu- } \\
\text { ments. } \\
\text { - In addition, citizens could model a cross-section of the street them- } \\
\text { selves. For this purpose, roadways of different widths were illus- } \\
\text { trated on posters. The modelling was done by simply sticking } \\
\text { scaled elements into the intended cross-section. For this purpose, } \\
\text { urban elements (e.g. road users, sidewalks, cycle lanes etc.) were } \\
\text { printed on paper and cut out in advance. }\end{array}$ & $\begin{array}{l}\text { - Digital projector } \\
\text { - A large printed plan map of } \\
\text { approx. 3x20 feet in size } \\
\text { placed on a row of tables. In } \\
\text { addition, existing traffic } \\
\text { lights and pedestrian cross- } \\
\text { ings were represented by } \\
\text { small physical traffic signs } \\
\text { - Poster, printed plans on tab- } \\
\text { letops } \\
\text { - Cardboard and paper model } \\
\text { elements } \\
\text { - Printed materials and photos, } \\
\text { paper note cards, pens, pins, } \\
\text { movable stands with bulletin } \\
\text { boards }\end{array}$ & $\begin{array}{l}\text { - The participants took the opportunity to write further comments on the local } \\
\text { plan map and discussed the available planning alternatives and comments in } \\
\text { smaller groups and with officials. } \\
\text { - The participants did not pay much attention to the posters, which were placed } \\
\text { next to the large printed plan map and contained detailed information on each } \\
\text { planning alternative. } \\
\text { - During intensive discussions, participants had to be actively reminded of the } \\
\text { possibility, or from the moderators' point of view, the necessity, to write down } \\
\text { comments in order to achieve a tangible discussion result. } \\
\text { - The concept of presenting the current state of discussions in a particular work- } \\
\text { ing group with written note cards on the bulletin board only worked to a lim- } \\
\text { ited extent: not everything was written down, only short statements that were } \\
\text { difficult to follow without further context from the discussion; the writing was } \\
\text { partly illegible, the cards were only roughly sorted thematically. } \\
\text { - The main points of discussion from the individual stands, working groups } \\
\text { only emerged in the final presentation, i.e. short summaries of about two } \\
\text { minutes. The speakers used the note cards written by the participants and their } \\
\text { own notes taken during and after the workshops. Focal points that also could } \\
\text { have been of interest to individual participants could not easily be discovered } \\
\text { during the workshops. }\end{array}$ \\
\hline & $\begin{array}{l}\text { - Redesign of a large urban area with three plan } \\
\text { sub-areas. At present in the phase of a test plan- } \\
\text { ning procedure: one of the central issues dealt } \\
\text { with is the question of the future spatial config- } \\
\text { uration of the today fragmented area. } \\
\text { - Workshops with three objectives based on each } \\
\text { other: 1) Inform and create understanding } \\
\text { among citizens about the different draft plans. } \\
\text { 2) Discuss drafts with other citizens, planners } \\
\text { and authorities and elaborate the advantages } \\
\text { and disadvantages of individual solutions. 3) } \\
\text { Generate written feedback on the various drafts, } \\
\text { individual themes (e.g. community open, green } \\
\text { space) and sub-areas. } \\
\text { - The results form the basis for a subsequent } \\
\text { online participation phase. }\end{array}$ & $\begin{array}{l}\text { - Officials and experts from three planning offices presented their } \\
\text { concepts and draft master plans. } \\
\text { - Experts from the jury committee commented on the respective } \\
\text { plans from their perspective. } \\
\text { - Discussion directly afterwards: the citizens could express their } \\
\text { spontaneous impressions and objections to the presented plans. } \\
\text { - During and after the presentations, the exhibition of the model and } \\
\text { posters could be viewed and ideas and comments on the plans } \\
\text { could be given with the help of notes and a bulletin board. } \\
\text { - For the following workshops, five stations were set up: one large } \\
\text { physical model, three MTT at which the various plans for three } \\
\text { sub-areas were illustrated in detail using digital } 3 \text { D design models } \\
\text { and specialist data, and a further station, where the participants } \\
\text { could submit their ideas on individual themes. } \\
\text { - Finally, the representatives who had been at the respective stations } \\
\text { summarized and presented the main results to the plenum. }\end{array}$ & $\begin{array}{l}\text { - Digital projector } \\
\text { - Wooden model (scale 1:500) } \\
\text { of the relevant urban area } \\
\text { - Posters with detailed infor- } \\
\text { mation on the three different } \\
\text { plans } \\
\text { - Large format plans and pa- } \\
\text { per maps on tabletops } \\
\text { - Paper note cards, pens, pins, } \\
\text { movable stands with bulletin } \\
\text { boards } \\
\text { - MTT with GIS and 3D- } \\
\text { design models of the plans }\end{array}$ & $\begin{array}{l}\text { - The physical models of the three drafts were alternately inserted into the large } \\
\text { wooden model of the area: a direct comparison of the differences in the con- } \\
\text { cepts was not feasible. } \\
\text { - At the MTT, the lack of storage space for blank note cards and pens repeat- } \\
\text { edly led to unwanted touch inputs that distupted the work process. } \\
\text { - The officials mainly operated the MTT. Citizens have rarely actively used the } \\
\text { MTT, for example to change the visible section of the area. } \\
\text { - The collection of comments from participants, an announced main objective } \\
\text { of the event, was effected exclusively in analog form with pen and paper. } \\
\text { - Comments were not geo-referenced. It therefore seems difficult to assign } \\
\text { them solely based on the actual rather short notes, particularly due to the large } \\
\text { fragmented plan area. Furthermore, it became apparent in the working ses- } \\
\text { sions and summarizing presentation that analog comments are difficult to sort } \\
\text { and link together. Thus, it is rather difficult to identify related comments and } \\
\text { organize the total feedback collected. } \\
\text { - The age range of the participants was large. Yet, the older participants were } \\
\text { obviously in the majority compared to the younger generations of citizens. }\end{array}$ \\
\hline
\end{tabular}


Table 3. Elicited requirements, explanations and exemplifying statements.

No. Explanation Example statements

R1.1 Media disruption/capturing and processing of comments: The analysis and transfer of comments on planning alternatives between the participation phases is an important and complex task. Therefore the collection of data and information at events should already be geared towards to the user's experiences and needs for the subsequent processing.

R1.2 Media disruption/data integration: To efficiently integrate data from on-site and online participation it must be feasible to use the data from online participation platforms in an appropriate digital form for on-site events and vice versa, i.e. on-site data should be digitally obtained for online use and further processing.

R2 Support discourse and decision-making: Digital tools combined with relevant data can support collaborative planning and decision-making. They must be designed to facilitate discourse, but a to enable results-oriented work and suppot leaming impacts on citizens' attitudes towards decisionmaking.
to

Obtain specific and detailed input: Comments from citizens should be worked out in detail and as precisely as possible. I.e. comments should be expressed in specific and detailed terms, contextualized with the planning alternative concerned, the specific geolocation and the type of comment (e.g. idea, criticism, and category).

R4.1 Manage expectations actively: Citizens should be transparently informed about the level of their participation and the extent to which their input are taken into account. Provide feedback whenever and as comprehensively as possible.

R4.2 Present results transparently: Analogous to the documentation of results with paper and pencil notes attached to bulletin boards, the current state of discussion at a particular place in the venue should be transparent for all participants and new arrivals. Further, captured comments must be easy to pick up for discussion.

R5.1 Support on-site analysis: Following the individual working sessions at different stations, the respective results are summarized and discussed in a plenary session. Therefore, it is necessary to
able to consolidate all comments, regardless of where they have been submitted. Yet the planning alternatives, variants, topics etc. to which the individual comments refer must remain comprehensible.

R5.2 Prepare the subsequent analysis: Categories, in particular, are essential for the subsequent processing of the data If comments are already categorized appropriately during the process, this facilites furter procesing the Teation and selection of categries should be designed accordingly.

R6.1 Design for diverse users: Citizen participation events are mostly public and any citizen of the city can come and participate. This leads to a large diversification of the potential user group.

R6.2 Usability for citizens: Citizens may use the applied technologies and tools for the first time. Therefore, tools must be designed in such a way that citizens can use them ad hoc and intuitively.

R6.3 Usability for authorities and associates: The tools must be accessible and comprehensible for the preparation and follow-up of participation events, i.e. independently of location and professional competence (e.g. planners, public officials, employees of public institutions, citizen participation

specialist

R7 Task support: Moderators and facilitators who are domain and mainly not IS experts should be able to offer subject- and tool-related help to citizens with questions or problems. Accordingly, the design must be such that the use of the tool is easy to explain and must not impose an additiona strong cognitive load on the moderators.

R8 Different participation processes for several projects are planned and implemented independently of each other. It must be ensured that all settings and parameters for the individual processes can be defined separately.

To digitize handwritten comments, some of which cannot be identified, is very time-consuming. External service agencies are commissioned for this. Up to the point that a citizen's opinion has been digitized, a lot of time and content is lost."; "For the processing f the participation, the data is analyzed using an Excel list, e.g. bad situation for pedestrians, or cars diving too fast. Then sorted manually by category. This is necessary so that the other engineering offices can work with it at all."

"The results from the online phase must also be prepared and shown. Comments were printed out to show how much different input was brought in. The comments were glued to the map by us to achieve transparency of the participation process. The amount of input should be visualized to make it clear to the citizens how much input was brought in."; "The comments at the events are collected via bulletin boards or stands and are then entered into an Excel file together with the comments from the online participation. The data is processed manually."; "We need to resolve the online-offline-discussion. A tool in which everything comes together."

"Digital data is very important to support the discussion. Having the discussion is very good, but you also have to get results. How do you organize that?"; "But then you have already talked about everything. Otherwise, it can shoot the project to pieces afterwards. Each participation process also brings up knowledge that is not yet known, i.e. local knowledge of the citizens"; "And it also has learning effects for citizens, a higher understanding why certain decisions are made."

"In order to visualize the effects on the traffic flow, e.g. in the case of changed bus routes or alternative pedestrian crossings, different traffic plans with specific traffic arrangements are used for comparison purposes."; "The semantic work with the comments is often very complicated and time-consuming, because terms are used differently by citizens or, from our perspective, incorrectly"; "Usually here is no geodata included."; "How do you make it possible to give meaningful feedback, so that these comments are more targeted, but there can still be general comments?"

,It is important to let citizens know what you will do with their input and what to expect next in the process, especially opportunities for ongoing participation."; "You always must give feedback at events on the extent to which the input from citizens has been incorporated. Of course you can't do that with every comment."; "An awareness of feasibility should be created. This prevents unrealistic requests."

"A problem we have also encountered with the use of touch tables is how to bring comments back into the discussion."; "There must be fedback so that citizens understand why certain decisions have been made."

"Often the process is such that planners can present their ideas, after which they work together with officials and citizens at individual ables. Afterwards all results are collected and handed over to the responsible party."; "There are various particular places at the event, comparable with exhibition stands at a trade fair, with tables, models, posters and so on, where citizens can discuss and elaborate on alternative plans and designs." "We receive the unsorted comments as CSV files and use Excel to move the comments manually. Comments can also be organized providing space to write down one or two sentences. The colors each define a category e.g. red housing, yellow traffic, and so on. Citizens could comment in this way and place the flags on the map."

"There must be something that is simple and accessible to everyone. Specifications, ideas, comments, all in one 'cloud'. It must be useful for all."; "The participants are very mixed in terms of age and experience, people are different."

"Digital tools must be developed in such a way that they can also be used offline, I mean on-site. Also to lower the barriers to get actively involved."

"Geo specialist data must be aligned with the data of the planning and area delimitation of the project, the layout should be adapted, but remain comprehensible for everyone. In the best case, the design is attractive."; "A web-based solution would make sense so that the remain comprehensible for everyone. In the best case, the design is attractive."; "A web-based solution
employees of the authorities, but also external partners, could access this application from anywhere."

"At the touch-tables, the moderators who operate the table often also provide assistance in using the table. If, for example, other spatial data layys are to be used for the current discussion, the moderator usually selects them. But if the citizens interact with the table, which they should, the moderator also supports them."

or each event the contents vary, such as planning alternatives and each event must therefore be tailored based on a basic concept."; Events are always different." 
citizens' private phones as input devices and the use of Quick Response codes (QR codes) in order to minimize sources of error and keep the user's effort low.

\section{Implementation}

Based on the initial concept, we have prototypically implemented distinct features in our tool that we describe in the following.

Comment feature - create comments with tagged QR codes. Comments in the scope of planning workshops usually have a spatial and non-spatial context, namely the geolocation associated with the comment, a category and sub-categories in which the comment can be classified (e.g. transport, cycle traffic or housing), and individual planning alternatives and variants to be discussed during the event. It is therefore rational to be able to annotate incoming comments with this context. The map can be used to find the exact location that applies to a comment. A pop-up window with an individual QR code is opened in the GIS when the MTT is touched. A citizen can now scan the $\mathrm{QR}$ code with a mobile device. The user is then redirected to a mobile web page where she/he can write a comment. The geo-coordinates are automatically saved with the comment according to the selected location in the GIS (the touchpoint on the MTT surface). As soon as a user scans a QR code, the pop-up window is closed. Further, preset categories can be selected. Categories are nested (e.g. "cycle paths" selected in the "traffic" category). A submitted comment is displayed in the GIS as a colored dot and can be opened, in a new pop-up, by touch. To make it easier to view comments, different colors are used for individual categories. When the user chooses a category, a certain corresponding color is assigned to the point on the map that is created subsequently. This makes it easier to categorize all comments and also provides a better overview on the displayed map. For easy understanding, a legend with the colors and the corresponding categories has been implemented. For intuitive use, the legend automatically folds out when the display of comments is activated and is hidden when the display function is deactivated. Besides, to avoid that (inaccurate) touching the screen opens a new QR code accidentally, we have added two sliders to the control menu to enable or disable the setting of new annotations or the display of existing annotations as needed, thus preventing errors (see figure 2). A comment can also be entered directly on the touch table. As already stated, due to the active integration of GIS and MTT functionalities to support the discourse, the use of a touch screen keyboard seems to be of limited use. In exceptions, for example, the moderator could use it to enter comments or to modify existing ones at the request of participants. For this purpose, the "local input" tab of the pop-up that opens

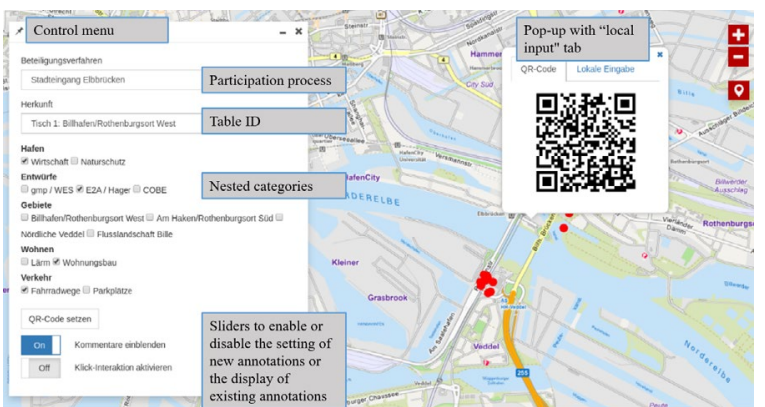

Figure 2. GIS-integrated tool. Own image with annotations.

is available. Against this background, the possibility of speech input was implemented, which however is not the focus of this research.

Presets allow easy commenting. For quick and intuitive commenting, the tool allows organizers of workshops (see paragraph Administration interface) to create and save presets for the recurring spatial and non-spatial attributes for later use by an event participant. These blueprints for comments are called presets. If the tool is started with a preset, all settings are taken from it and preselected in the comment feature. This is possible for the categories, the location on the map, and also for the beginning of a comment itself, e.g. if some additional information included should be obligatory. Access to the comment feature with a preset is done via a unique Uniform Resource Identifier (URI). For easy access, a QR code is created for each preset in which this URI is encoded. Such QR codes should then be created by the organizers of a workshop in the administration interface and attached to specific venue points, e.g. planning alternativerelated working stations, of the event (we call these specific sources in the following "origin"). We take advantage of the fact that e.g. for a certain poster it is known what exactly is displayed. That is, e.g., which planning office is responsible for it and which local authorities are involved. It is also conceivable to apply a larger number of QR codes to an exhibited city model, so that the geolocation is already pre-selected and does not have to be chosen by citizens. Therefore, presets are especially useful for bridging the gap between analog and digital workshop tools. Presets can also be used with GIS on the MTT, if preselected attributes are necessary. Here again a QR code is created by users touching the MTT and, as before, can be scanned with a smartphone, for example, and the actual commenting can then take place on the user's device. After scanning, the QR code is closed as well.

Display comments and encourage discourse- discussion feed feature. In order to provide immediate feedback to participants of events, incoming comments can be displayed in a feed together with the GIS (see figure 3). New comments appear on the map as colored dots, with the most recent comment represented by a larger 


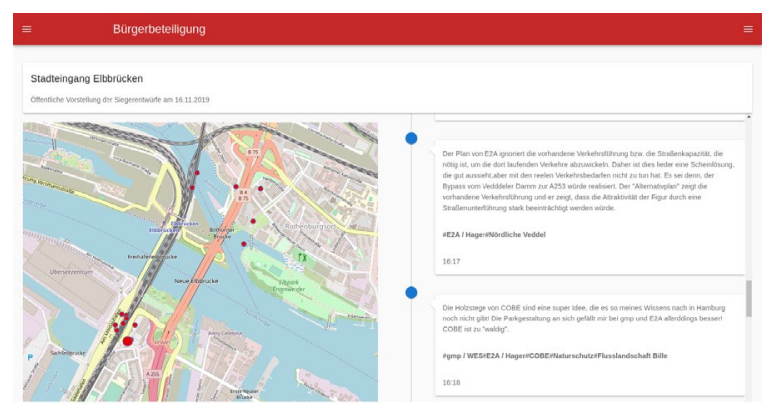

Figure 3. Discussion feed with incoming comments. Own image.

dot. In the feed, new comments are added below. The list of comments scrolls down automatically, so that the latest comments are always visible. The categories of comments are displayed in the feed marked with a hashtag. The architecture provides a filter function for comments. This allows to display only comments from an origin or from one or more categories. Sometimes, it may be useful to display only the comments from the table of the current discussion, or from other tables, too. Each table has its own table ID, which gives moderators the possibility to change the displayed contributions via table ID. Therewith, the feed feature is useful for individual working and plenary sessions. If deployed on large displays in the plenum, e.g. on a stage, participants can identify focal points and discover interesting places of discussions. Further, the feed feature can be used at the individual stations where comments can be made. For example, users at a MTT or in front of a model can see that their comments have been received and the current discussion status at a particular location is transparent for all new joining participants. Through the direct transparent presentation, we are aiming for a higher willingness to participate. In particular, the display of comments in the GIS could also offer the moderators on-site the possibility of ad hoc analysis, thus to address areas and issues of the presented planning that have not yet been intensively discussed and to specifically ask for feedback from participants.

Administration interface-Prepare on-site events. The administration interface is used for the configuration of events by the responsible authorities. In order that different participation procedures can be planned and carried out independently of each other, all settings for the individual procedures must be made separately. It is therefore possible to create, edit and delete categories and presets for each event. Categories are nested (see above). In the final state of the admin feature, the nesting of categories should be intuitively changeable, for example by moving the categories via drag and drop. In the implemented prototype, however, categoriesand subcategories can already be created and edited.
A main functionality of the administration interface is the preselection of attributes for commenting by the described presets. In order to create the corresponding QR codes easily, a graphic can be created for each preset that contains the QR code, a stylized smartphone, the associated categories and the geocoordinates of the preset. To enable a filtered feed, the origin (see above) of each comment is recorded. These origins are managed via the administration interface in the same way as the categories. For MTT the number of tables and the corresponding IDs can be selected. To control access to the administration interface, users can be displayed, added, and removed.

\section{Discussion}

In this paper, a concept and a prototypical tool that enable citizens to comment via GIS and MTT in a context-related and intuitive way using mobile devices during participatory planning events were presented. Therewith, we address specific problems of on-site planning workshops and informal integrated citizen e-participation, i.e. the need to digitally obtain input and overcome media disruptions for the further processing within the planning and participation process. Through the observations of different participatory planning workshops, subsequent scientific reflections on the observed interactions, and interviews with domain experts, Rs were elaborated and prototypically instantiated. Table 3 presents a summary showing the specific Rs for the design cycle. We have developed a prototype and stopped at the proofof-concept, with the possibility of further development in future research projects. Therewith, we expand the applicable knowledge base by adding prescriptive knowledge to literature.

The developed prototype has three core features: 1. Obtain comments: New comments can be generated during workshops by scanning a $\mathrm{QR}$ code directly from the GIS or a specific source. The QR code is unique and the comment is pre-keyworded, geo-referenced and comprehensible by origin and category. 2. Display comments: During the event, a feed can be displayed to give participants an overview of the current discussion at different locations during the event. This feed can also be displayed parallel to the GIS, which shows all incoming comments live. This also makes it easier for the moderators to give all participants an overview of the discussion results at the end of the event and to summarize comments from breakout groups to the plenum. 3. Administration: The setup of the specific event is configured via an administration interface, which also allows, e.g., the download of pre-tagged and geolocated QR codes and the setup of specific MTT. 
The evaluation with the expert group confirmed the easy handling of the tool for users and integration into the GIS architecture. The potential added value for the interaction between citizens and authorities at the MTT on the basis of the digitally obtained and visualized comments by a feed was particularly noteworthy. Moreover, the easy online publication of commented plans and models for citizen information as well as the possibility of extrapolating planning objects without media disruption were identified as promising capabilities of this tool.

Nevertheless, our work has some limitations. We identified specific Rs with domain experts and designed the tool to be intuitive and easy to use. Despite this fact, we did not evaluate the tool's capabilities in a real-world setting. We acknowledge that we simply have not been in a position to address all the overarching objectives of civic participation, such as considering the challenges of the digital divide and social selectivity $[23,26]$. In this regard, e.g., the user interface of the prototype is not barrier-free. People with color blindness could have problems with the display, as information is transmitted with the use of color. Future research should investigate the general use of such technologies or required context-related modifications to foster inclusive participation. In this light, text-to-speech and speech-to-text features may also support inclusiveness. A conceivable application concept that should be tested in the future would be that participants or the moderators record the results of a discussion via microphone. While the speech-to-text function is already implemented in the prototype, future research should evaluate the possible applicability in personal interaction in the group. That is, the participants discuss a topic or problem until it appears sensible to document a result and then the ideas are captured by the active notice of the moderator. Thus, the focus shifts to the collaborative documentation of a group result. In this scenario, it would also be worth considering the use of natural language based assistants, which support the group discussion and actively and situationally engage in order to document results together with the participants.

Moreover, an integrated approach to the use of the tool should be developed. That is, only if the GIS-integrated tool is methodically encapsulated in working practices, it can contribute to problem solving on the basis of the design approach, e.g. to facilitate detailed and contextualized contributions from citizens that can be more effectively processed and transferred to subsequent participation phases and amongst online and offline elements [30]. Despite the implemented preset function for categories and the possibility to define keywords, the comments still have to be manually distilled and analyzed. This applies to the ad hoc analysis in workshops on-site, e.g. in order to identify related comments and key topics and present them to the plenum, as well as in the follow-up of comments from events. The use of AI-based text analysis instruments seems to be a promising approach, specifically in the participatory planning domain, which will gain further importance in practice and research in the future.

\section{References}

[1] Anttiroiko, A.-V., "Urban Planning 2.0", International Journal of E-Planning Research, 1(1), 2012, pp. 1630.

[2] Behörde für Stadtentwicklung und Wohnen Hamburg Stadtwerkstatt, Digital Citizen Participation in Hamburg Online \& On-site, 2019.

[3] Bittner, E.A.C., G.C. Küstermann, and C. Tratzky, "The facilitator is a Bot: towards a conversational agent for facilitating idea elaboration on idea platforms", European Conference on Information Systems, 2019.

[4] Böhm, M., "Bürgerbeteiligung nach Stuttgart 21: Änderungsbedarf und-perspektiven", Natur und Recht, 33(9), 2011, pp. 614-619.

[5] Brabham, D.C., "Crowdsourcing the Public Participation Process for Planning Projects", Planning Theory, 8(3), 2009, pp. 242-262.

[6] Brettschneider, F., "Großprojekte zwischen Protest und Akzeptanz: Legitimation durch Kommunikation", in Stuttgart 21: Ein Großprojekt zwischen Protest und Akzeptanz, F. Brettschneider and W. Schuster, Editors. 2013. Springer VS: Wiesbaden.

[7] Brettschneider, F., Gesetzgebung mit Bürgerbeteiligung, Springer Fachmedien Wiesbaden, Wiesbaden, 2019.

[8] Bundesministerium für Verkehr und digitale Infrastruktur, Handbuch für eine gute Bürgerbeteiligung: Planung von Großvorhaben im Verkehrssektor, 2014.

[9] Chandra, L., S. Seidel, and S. Gregor, "Prescriptive Knowledge in IS Research: Conceptualizing Design Principles in Terms of Materiality, Action, and Boundary Conditions", 48th Hawaii International Conference on System Sciences, 2015.

[10] Dicicco-Bloom, B. and B.F. Crabtree, "The qualitative research interview", Medical education, 40(4), 2006, pp. 314-321.

[11] Falco, E. and R. Kleinhans, "Beyond technology: Identifying local government challenges for using digital platforms for citizen engagement", International Journal of Information Management, 40, 2018, pp. 17-20.

[12] Gil, O., M.E. Cortés-Cediel, and I. Cantador, "Citizen Participation and the Rise of Digital Media Platforms in Smart Governance and Smart Cities", International Journal of E-Planning Research, 8(1), 2019, pp. 1934.

[13] Gregor, S., "The Nature of Theory in Information Systems", MIS Quarterly, 30(3), 2006, p. 611.

[14] Gregor, S. and A.R. Hevner, "Positioning and Presenting Design Science Research for Maximum Impact", MIS Quarterly, 37(2), 2013, pp. 337-355. 
[15] Groot, B.P., R. Effing, and M.J.A. Veenstra, "Urban Media Trends for Enabling Citizen Participation in Urban Planning: Old Wine in New Barrels?", in Electronic Participation, N. Edelmann, P. Parycek, G. Misuraca, P. Panagiotopoulos, Y. Charalabidis, and S. Virkar, Editors. 2018. Springer International Publishing: Cham.

[16] Healey, P., "Planning through debate: The communicative turn in planning theory", Town Planning Review, 63(2), 1992, p. 143.

[17] Hevner, A.R., "A three cycle view of design science research", Scandinavian journal of information systems, 19(2), 2007, p. 4.

[18] Hevner, A.R., S.T. March, J. Park, and S. Ram, "Design Science in Information Systems Research", MIS Quarterly, 28(1), 2004, pp. 75-105.

[19] Hofmann, M., S. Münster, and J.R. Noennig, "A Theoretical Framework for the Evaluation of Massive Digital Participation Systems in Urban Planning", Journal of Geovisualization and Spatial Analysis, 4(1), 2020.

[20] Kaczorowska, A. and M.B. Pont, "Modelling Urban Environments to Promote Ecosystem Services and Biodiversity", International Journal of E-Planning Research, 8(3), 2019, pp. 1-12.

[21] Kitchin, R., T.P. Lauriault, and G. McArdle, eds., Data and the city, Routledge Taylor \& Francis Group, London, New York, 2018.

[22] Lodigiani, A., "E-Planning: The Digital Toolbox in Participatory Urban Planning", in Innovative Technologies in Urban Mapping, A. Contin, P. Paolini, and R. Salerno, Editors. 2014. Springer International Publishing: Cham.

[23] Martini, M. and S. Fritzsche, "Kompendium OnlineBürgerbeteiligung", 2015.

[24] Mayring, P., "Qualitative Inhaltsanalyse", in Handbuch qualitative Forschung in der Psychologie. 2010. VS Verlag: Wiesbaden.

[25] Mueller, J., H. Lu, A. Chirkin, B. Klein, and G. Schmitt, "Citizen Design Science: A strategy for crowd-creative urban design", Cities, 72, 2018, pp. 181-188.

[26] Norris, P., Digital Divide: Civic Engagement, Information Poverty, and the Internet Worldwide, Cambridge University Press, Cambridge, 2001.

[27] Nummi, P., S. Eräranta, and M. Kahila-Tani, "Enhancing E-Participation in Urban Planning Competitions", in New Approaches, Methods, and Tools in Urban EPlanning, I. Dima and C. Nunes Silva, Editors. 2018. IGI Global.

[28] Nunes Silva, C., "Introduction", in Citizen-Responsive Urban E-Planning, C.N. Silva, Editor. 2020. IGI Global.

[29] Paulus, P.B. and J. Baruah, "Enhancing Creativity in E-Planning", in New Approaches, Methods, and Tools in Urban E-Planning, I. Dima and C. Nunes Silva, Editors. 2018. IGI Global.
[30] Poser, M., G. Küstermann, and E. Bittner, "Citizen EParticipation: Bringing the "E" to Facilitated Workshops", 52nd Hawaii International Conference on System Sciences, 2019.

[31] Sanford, C. and J. Rose, "Designing the e-participation artefact", International Journal of Electronic Business, 6(6), 2008, p. 572.

[32] Schmalz, I.M., Akzeptanz von Großprojekten, Springer Fachmedien Wiesbaden, Wiesbaden, 2019.

[33] Selle, K., B. Rösener, and M. Rössig, eds., Planung und Kommunikation: Gestaltung von Planungsprozessen in Quartier, Stadt und Landschaft, Bauverlag, Wiesbaden, Berlin, 1996.

[34] Stelzle, B. and J.R. Noennig, "A method for the assessment of public participation in urban development", Urban Development Issues, 61(1), 2019, pp. 33-40.

[35] Talen, E., "Bottom-Up GIS", Journal of the American Planning Association, 66(3), 2000, pp. 279-294.

[36] Thorpe, A., "Rethinking Participation, Rethinking Planning", Planning Theory \& Practice, 18(4), 2017, pp. 566-582.

[37] Vogel, D. and B.J. Funck, Immer nur die zweitbeste Lösung? Protokolle als Dokumentationsmethode für qualitative Interviews, Mannheim, 2018.

[38] Voorberg, W.H., V.J.J.M. Bekkers, and L.G. Tummers, "A Systematic Review of Co-Creation and CoProduction: Embarking on the social innovation journey", Public Management Review, 17(9), 2015, pp. 1333-1357.

[39] Wallin, S., J. Saad-Sulonen, M. Amati, and L. Horelli, "Exploring E-Planning Practices in Different Contexts", International Journal of E-Planning Research, 1(3), 2012, pp. 17-39.

[40] Wirtz, B.W., P. Daiser, and B. Binkowska, "E-participation: A Strategic Framework", International Journal of Public Administration, 41(1), 2018, pp. 1-12.

[41] Yamu, C., A. Poplin, O. Devisch, and G. de Roo, The virtual and the real in planning and urban design: perspectives, practices and applications, Routledge, 2017

[42] Zilleßen, H., "Die Modernisierung der Demokratie im Zeichen der Umweltproblematik", in Umweltpolitik als Modernisierungsprozeß: Politikwissenschaftliche Umweltforschung und -lehre in der Bundesrepublik Deutschland, V. Prittwitz, Editor. 1993. VS Verlag für Sozialwissenschaften: Wiesbaden. 